\title{
Progressive language impairment without dementia: a case with isolated category specific semantic defect
}

\author{
ANNA BASSO, ${ }^{*}$ ERMINIO CAPITANI, $\dagger$ MARCELLA LAIACONA $\dagger$ \\ From the Second* and First $\dagger$ Clinics for Nervous Diseases, Milan University, Milan, Italy
}

SUMMARY A patient is described with a 5 year progressive defect of naming and auditory verbal comprehension, the pathological nature of which was presumably degenerative. The auditory comprehension defect unevenly affected different semantic categories, and was particularly severe for the names of animals, fruits and vegetables. The patients showed loss of the verbal knowledge of the physical attributes of the concepts corresponding to the words he was unable to understand, and sparing of the verbal knowledge of the functional attributes. His performance was defective also on the colour-figure and sound-picture matching test.

Disturbances of naming and auditory verbal comprehension are basic symptoms of aphasia. Most patients, however, have a degree of residual naming and ability to comprehend the most frequently used words.

A number of recent case reports show that the sparing of some items (or selective impairment) in naming and comprehension tasks can be governed by different rules, that is, by the semantic category of the stimulus, although few data are available to indicate how frequently an uneven pattern of performance according to the semantic category is found in the general aphasic population. ${ }^{1}$ The first dissociation described was between impairment of object name comprehension and preservation of the comprehension of names of foods, animals and flowers; ${ }^{2}$ subsequently the opposite pattern was observed, for both word comprehension ${ }^{3}$ and naming. ${ }^{4}$

We describe a further example of the latter kind of dissociation, which was particularly evident in word comprehension. Our patient was affected by a slowly progressive language impairment as an isolated symptom over a period of 5 years, which probably fits into the form of progressive aphasia without dementia, considered by Mesulam ${ }^{6}$ to be a focal cerebral degeneration of the left perisylvian region.

Names of authors are in alphabetical order.

Address for reprint requests: E. Capitani, MD, Clinica Neurologica Università di Milano, Ospedale S. Paolo, via Di Rudinì 8, 20142 Milano, Italy.

Received 28 August 1987 and in revised form 5 April 1988. Accepted 11 April 1988

\section{Case report}

A 73 year old right-handed man, NV, complained of progressive word-finding difficulty. The patient was a retired electrician with 5 years of schooling. His previous medical history indicated no neurological disturbances, nor did any neurological disease affect his family. The neurological examination was normal except for the presence of the snout reflex.

His troubles had first appeared 5 years before, with difficulty in finding proper names; two years later he experienced difficulty while shopping for food and while ordering in a restaurant. His performance progressively deteriorated, and 1 year later he was unable to name the different kinds of food: this was evident both shopping and at a restaurant, where he had to resort to the help of his wife to communicate his choices. The next step was the appearance of word comprehension difficulties that slowly worsened. CT in June 1986 after the neurological consultation showed moderate diffuse atrophy (consistent with his age), asymmetrical enlargement of the left lateral ventricle, especially of the temporal horn, and asymmetrical widening of the left Sylvian fissure and of the sulci of the temporal operculum. Moreover, a small hypodense area was discovered in the body of the left caudate nucleus (fig). Doppler sonography of the cerebral arteries performed at the same time did not show any abnormality.

\section{Neuropsychological assessment}

1 General language examination The patient was given the standard Language Examination currently in use in our Aphasia Unit. ${ }^{7}$ His verbal output was sufficiently informative, without articulatory defects but with frequent wordfinding difficulties. In the oral confrontation naming test, when faced with word-finding difficulties, he fluently produced circumlocutions, correctly naming only eight of 20 pictures. Written expression was similarly affected. Some- 
times he did eventually find the correct name for the stimulus, but this often appeared strange and alien to him. Auditory and written comprehension of single words and simple sentences were almost correct, but when the choice was among semantically similar alternatives NV had considerable difficulties, and he only correctly pointed to 11 of 20 pictures named by the examiner. Repetition, reading aloud, writing to dictation and copying were normal. Auditory verbal comprehension, assessed by means of the Token
Test, ${ }^{8}$ was normal, with a score of $32 / 36$. The patient underwent language rehabilitation for 3 months. The second language examination, 7 months after the first, revealed little change.

2 General neuropsychological examination NV underwent a large number of additional neuropsychological tests, (repeated after 7 months) for evaluation of language, intelligence, memory and visuoperceptual abilities. The results
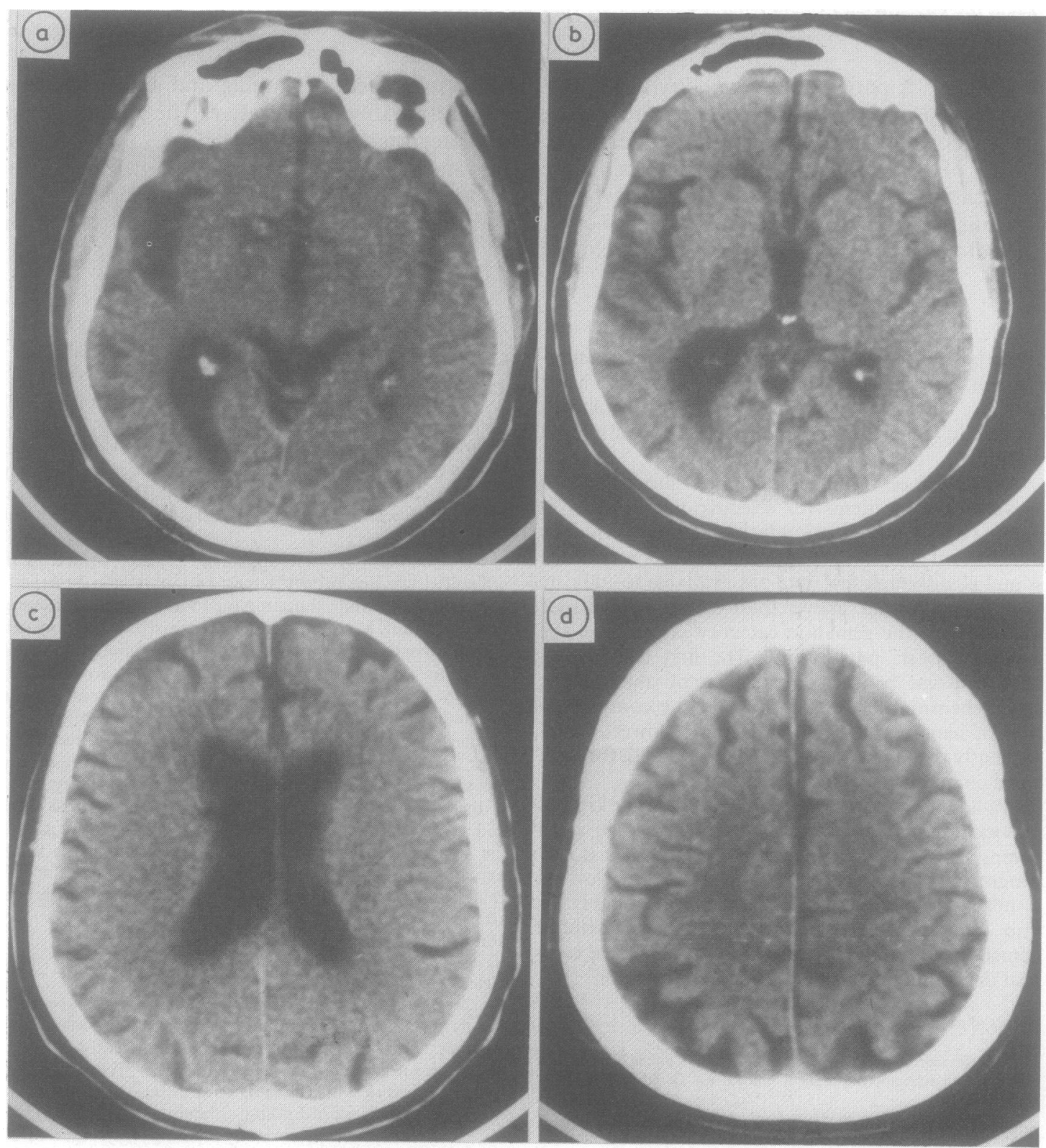

Fig

CT scan of the patient. Left side of the brain on the left. 
are shown in the Appendix. For most neuropsychological tests, the scores could be expressed in terms of Equivalent Scores, ${ }^{9}$ calculated on the ranks of the original scores adjusted for age, education (and for the influence of the patient's sex when appropriate): 0 corresponds to a score lower than the inferential 5th centile of the normal population with $95 \%$ confidence; 4 corresponds to a score higher than the median value of the normal population, and 1,2 , and 3 are intermediate points between 0 and 4 on a quasiinterval scale. Part of these norms were calculated for 321 normals by a Cooperative Italian Study. ${ }^{10}$ For other tests, the scores could be converted into Equivalent Scores, since the published norms report the ranks of the scores adjusted for age, education and sex. ${ }^{11}$ Finally, the results of some tests could only be given in terms of normal or pathological performance. Details of the test employed are reported in the cited papers. In the colour-figure matching test the patient had to indicate among 30 coloured pencils the one which best corresponded to the colour of eight objects represented by black and white outline drawings. In the sound-picture matching test the patient was requested to hear a meaningful noise (through a headphone), and then to indicate among four alternatives the picture which corresponded to the natural source of the noise; the test included 20 different noises.

As shown in the Appendix, NV's performance was defective only in naming tasks (either on description or on confrontation), in verbal fluency with semantic cue (animals, fruits and make of cars) and in the colour-figure and soundfigure matching tests. It is worth noting that NV scored above the median for normals in a wide range of tasks, and was on the lower-band of normality only for verbal fluency (on phonological cue), in the oral apraxia test and in bysyllabic word span.

3 Naming: effect of frequency, concreteness and type of presentation We then decided to investigate more extensively the naming difficulties. We used the material by Novelli et $a l^{12}$ which includes (1) naming of 32 common objects (from black and white photographs taken from the "usual" perspective), and (2) naming of 38 items to description (28 concrete and 10 abstract). We studied the effects of word frequency, of the abstract/concrete type, and, within concrete stimuli, the effect of the type of presentation (confrontation naming vs naming to description). The analysis was carried out by logistic regression. Here and in the following analyses each factor was studied within the overall statistical design, in order to evaluate each effect adjusted for the correlation shared with the others (that is, independently of the other terms). No worsening between the first and second examination was discovered (Chi-Square $<1, \mathrm{df}=1$, $\mathrm{p}=\mathrm{NS}$ ). On the whole, $\mathbf{N V}$ was able to name correctly 22 pictures out of $64(34 \%)$ and to name 22 out of 76 items from description (28.9\%): among the latter, he named three of 20 abstract words $(15 \%)$ and 15 of 56 concrete $(33.9 \%)$.

The type of presentation (description vs. confrontation) did not influence performance (Chi-Square $<1, \mathrm{df}=1$, $p=N S$ ). Frequency of the words to be named (total frequency of the word in the Italian language according to Bortolini et al, ${ }^{13}$ was found to be highly significant (ChiSquare $=49 \cdot 310$, df $=1, p<0.0001$ ) and concrete words were named better than abstract words (Chi-Square = 18.240, df $=1, \mathrm{p}<0.0001$ ).
The consistency between the first and the second examinations was high: 62 out of 70 words yielded the same outcome at the second session, five were named on the first but not on the second and three vice versa. These figures were analysed by the k-coefficient, ${ }^{14}$ which is a measure of agreement for nominal scales that yields values similar to the correlation coefficient $(+1$ is perfect agreement and 0 perfect independence between the two sessions). In this case, $\mathrm{k}$ had a value of 0.735 , indicating a very significant agreement between the first and second examinations $(p<0.0001)$.

4 Picture naming: category effect $\mathrm{A}$ further question concerned the category effect. The clinical story of the patient indicated that his troubles had been impressive for naming foods, and this was fully confirmed by the clinical examination, as he was unable to produce the names of foods or to describe a meal. This contrasted with some residual naming ability for other categories. We used the pictures of Snodgrass and Vanderwart. ${ }^{15}$ The category "foods" is not extensively represented per se, but there are plenty of stimuli representing fruits and vegetables. The patient was given the pictures one at a time and asked to name them. For the picture-naming task we employed 60 stimuli belonging to six categories (table 1): three categories refer to living things, that is, animals, fruits and vegetables, and body parts; and three to non-living things, that is, inanimate objects, means of transport, and musical instruments. We decided not to collapse means of transport and musical instruments into the same category of the other non-living things, as these categories have a rather homogeneous and distinct function. The logistic regression indicated (1) a very significant effect of word frequency, (2) no difference between the first and second examination, and (3) a significant category effect even after adjustment for the frequency difference between categories. Having five degrees of freedom, we chose to compare the category "animals" with the others. The outcome was a significant difference between animals and means of transport. The lack of difference between animals and body parts has to be interpreted as an effect of the covariance for word frequency between two categories, whose mean difference in frequency is overwhelming.

5 Verbal fluency on different categories In addition to the verbal fluency examination made in the preliminary neuropsychological assessment, verbal fluency from these semantic cues was also examined with a time limit of one minute for each category; the patient was able to produce one name for "animals", none for "fruits and vegetables", three for "inanimate objects" and six for "means of transport".

6 Auditory verbal comprehension: category effect Subsequently NV was asked to indicate the picture named by the examiner among 10 alternatives belonging to the same semantic category (that is, animals, body parts, etc.). In this task (table 2), the effect of word frequency was confirmed, as was the lack of worsening after 7 months. Here the category effect was even more significant than that of frequency, and the category pattern was similar to (though not fully coincident with) that observed in naming. Again, animals scored worst $(7 / 20)$, but fruits and vegetables $(7 / 20)$ were at the same level. Comprehension of names of inanimate objects was almost perfect (19/20). Comprehension of animals was 
Table 1 Picture naming in different semantic categories

\begin{tabular}{|c|c|c|c|c|c|c|}
\hline $\begin{array}{l}\text { Category } \\
\text { Mean frequency* }\end{array}$ & $\begin{array}{l}\text { Animals } \\
(3 \cdot 70, S D 4 \cdot 14)\end{array}$ & $\begin{array}{l}\text { Fruits and } \\
\text { vegetables } \\
(8 \cdot 00, S D 9.88)\end{array}$ & $\begin{array}{l}\text { Inanimate } \\
\text { objects } \\
(18 \cdot 20, S D 35 \cdot 48)\end{array}$ & $\begin{array}{l}\text { Means of } \\
\text { transport } \\
(30 \cdot 26, S D 30 \cdot 86)\end{array}$ & $\begin{array}{l}\text { Musical } \\
\text { instruments } \\
(2 \cdot 30, S D 5 \cdot 50)\end{array}$ & $\begin{array}{l}\text { Body parts } \\
(122 \cdot 80, S D 120 \cdot 31)\end{array}$ \\
\hline $\begin{array}{l}\text { 1st Examination } \\
\text { 2nd Examination } \\
\text { Total }\end{array}$ & $\begin{array}{l}0 / 10 \\
0 / 10 \\
0 / 20\end{array}$ & $\begin{array}{l}2 / 10 \\
1 / 10 \\
3 / 20\end{array}$ & $\begin{array}{l}2 / 10 \\
1 / 10 \\
3 / 20\end{array}$ & $\begin{array}{r}5 / 10 \\
7 / 10 \\
12 / 20\end{array}$ & $\begin{array}{l}2 / 10 \\
0 / 10 \\
2 / 20\end{array}$ & $\begin{array}{r}7 / 10 \\
6 / 10 \\
13 / 20\end{array}$ \\
\hline
\end{tabular}

Frequency: Chi-Square $=30.67$ df $=1 \quad p<0.0001$

Evolution: Chi-Square $=<1 \quad$ df $=1$ NS

Category: Chi-Square $=13.18$ df $=5 \quad \mathrm{p}=0.022$

*Mean frequency of the corresponding names in the Italian language (13).

Here and in the following table the effect of each factor was evaluated independently of that of the others (see Text).

Consistency between 1st and 2nd examination:

$$
\mathrm{k}=0.625 \quad \mathrm{~s}(\mathrm{k})=0.115 \quad \mathrm{z}=5.423 \quad \mathrm{p}<0.0001
$$

Table 2 Auditory verbal comprehension in different semantic categories

\begin{tabular}{|c|c|c|c|c|c|c|}
\hline $\begin{array}{l}\text { Category } \\
\text { Mean frequency* }\end{array}$ & $\begin{array}{l}\text { Animals } \\
(3 \cdot 70, S D 4 \cdot 14)\end{array}$ & $\begin{array}{l}\text { Fruits and } \\
\text { vegetables } \\
(8 \cdot 00, S D 9 \cdot 88)\end{array}$ & $\begin{array}{l}\text { Inanimate } \\
\text { objects } \\
(18 \cdot 20, S D 35 \cdot 48)\end{array}$ & $\begin{array}{l}\text { Means of } \\
\text { transport } \\
(30 \cdot 26, S D 30 \cdot 86)\end{array}$ & $\begin{array}{l}\text { Musical } \\
\text { instruments } \\
(2 \cdot 30, S D 5 \cdot 50)\end{array}$ & $\begin{array}{l}\text { Body parts } \\
(122 \cdot 80, S D 120 \cdot 31)\end{array}$ \\
\hline $\begin{array}{l}\text { 1st Examination } \\
\text { 2nd Examination } \\
\text { Total }\end{array}$ & $\begin{array}{l}4 / 10 \\
3 / 10 \\
7 / 20\end{array}$ & $\begin{array}{l}5 / 10 \\
2 / 10 \\
7 / 20\end{array}$ & $\begin{array}{r}9 / 10 \\
10 / 10 \\
19 / 20\end{array}$ & $\begin{array}{l}10 / 10 \\
10 / 10 \\
20 / 20\end{array}$ & $\begin{array}{r}4 / 10 \\
6 / 10 \\
10 / 20\end{array}$ & $\begin{array}{r}9 / 10 \\
10 / 10 \\
19 / 20\end{array}$ \\
\hline
\end{tabular}

Frequency: Chi-Square $=6.540$ df $=1 \quad p<0.0001$

Evolution: Chi-Square $=<1$ df $=1$ NS

Category: Chi-Square $=37.490$ df $=5 \quad p<0.0001$

Consistency between 1st and 2nd examination:

*See table 1.

$$
\mathrm{k}=0.538 \quad \mathrm{~s}(\mathrm{k})=0.119 \quad \mathrm{z}=4.509 \quad \mathrm{p}<0.0001
$$

significantly poorer than that of inanimate objects and transport means (20/20), while that of body parts (19/20) was not significantly different due to the adjustment for frequency, and musical instruments scored at an intermediate level (10/20).

We investigated whether the characteristics of the pictures did influence the performance. According to the analysis of Snodgrass and Vanderwart, ${ }^{15}$ "image complexity" refers to the amount of line intricacy of the drawing, "image agreement" indicates how closely each picture resembles the "mental image" of the object, and "familarity" indicates how usual the object is in the realm of experience; the values of these parameters for each picture are reported in. ${ }^{15}$ The values of "image complexity" and "image agreement" did not differ for pictures matched and those not matched with the name, whereas the "familiarity" was significantly different $(t=5.46, \mathrm{df}=106, \mathrm{p}<0.001)$. Since "familiarity" is the pictorial equivalent of the word frequency, and the latter was included in the statistical design, we are confident that it did not bias the category differences.

These findings confirm that NV had naming and, more markedly, word comprehension difficulties that were uneven for different categories; animals and fruits and vegetables appeared to be affected most severely. This replicates a pattern found by other authors.

We then investigated two further aspects: (1) do the category specific troubles of NV affect non-verbal tasks? and (2) can the words that he does not understand still evoke some fragment of meaning?

7 Visual categorisation We examined the ability of NV in a visual categorisation task carried out with a series of Snodgrass and Vanderwart's pictures that included, among others, the same stimuli used in the naming and comprehension tasks. Pictures representing category prototypes were exposed in front of the patient, and he had to attribute to the appropriate category pictures subsequently given in random order putting them near the prototype. NV had first to categorise pictures assigning them to the prototypes of animals, fruits and vegetables, inanimate objects and means of transport (prototypes were dog, apple, key and truck); subsequently the exposed prototypes represented mammals (dog), birds (sparrow) and insects (fly); fruits (apple) and vegetables (carrot); and tools (hammer), furniture (bed) and kitchen and table utensils (glass). NV's performance was perfect while categorising between animals, fruits, inanimate objects, means of transport $(40 / 40)$ or between different animals (27/27); within fruit and vegetables he scored $12 / 18$ (chance $=9$, SD 2.1) and within inanimate objects he scored 23/25.

One must be cautious in the evaluation of this result, as the difficulty of the task could be different among categories.

8 Residual verbal comprehension: different levels of semantic representation To evaluate the partial residual verbal comprehension of $\mathrm{NV}$, we considered the stimuli for which he had been unable to match correctly name to picture in the first and/or second examination: these were 38 (13 animals, 13 fruits and vegetables, 1 inanimate object, 10 musical instruments, 1 body part: see table 2). For each stimulus, the patient had to answer a series of questions such as: "is the crocodile an animal, an object or a flower?" The task was entirely verbal, and the questions were concerned with different levels and distinct aspects of the semantic representation of the corresponding concept, as shown in table 3 . The outcome (table 3 ) was that our patient performed well with 
Progressive language impairment without dementia: a case with isolated category specific semantic defect 1205

Table 3 Partial residual verbal comprehension of the words that the patient was unable to match with the corresponding picture

\begin{tabular}{|c|c|c|c|c|}
\hline Level of knowledge & Example & Offered alternatives & Chance & Correct answers ${ }^{*}$ \\
\hline Superordinate (upper level) & $\ldots$ is an object an animal & 3 & $11 \cdot 33 / 34$, SD $2 \cdot 75$ & $31 / 34$ \\
\hline Superordinate (lower level) & $\begin{array}{l}\text {... is a bird, mammal, fish } \\
\text { or reptile? }\end{array}$ & 4 & $5 \cdot 75 / 23$, SD $2 \cdot 08$ & $5 / 23$ \\
\hline Functional attributes & $\begin{array}{l}\ldots \text { does it live in Italy or } \\
\text { in the desert? }\end{array}$ & $\begin{array}{l}2 \\
2\end{array}$ & $\begin{array}{r}6 \cdot 50 / 13, \text { SD } 1 \cdot 80 \\
14 \cdot 50 / 29, \text { SD } 2 \cdot 69\end{array}$ & $\begin{array}{l}10 / 13 \\
25 / 29\end{array}$ \\
\hline Sensory attributes & $\begin{array}{l}\text {.. does it have a smooth back } \\
\text { or is it humpbacked? }\end{array}$ & 2 & $10 \cdot 00 / 20$, SD $2 \cdot 24$ & $10 / 20$ \\
\hline
\end{tabular}

*Not all the 38 words could be investigated at all the levels of semantic knowledge.

upper level superordinates and with functional attributes, but successful responses were at the level of chance for lower level superordinates and sensory attributes. For the words that he was able to match with pictures the correct answers regarding functional attributes were $90 \%(77 / 86)$, a percentage similar to that $(25 / 29=86 \%)$ observed for the words he had been unable to understand. For physical attributes, with words correctly matched with picture correct judgements were $72 \%(23 / 32)$, whereas the percentage with non-comprehended words was $50 \%(10 / 20)$.

The analysis of these data showed that the effect of attribute type (functional versus physical) was highly significant (Chi-Square $=12.754, \mathrm{df}=1, \mathrm{p}<0.001)$; performance with the words that the patient was able to match with picture was better than with words he was unable to match, but this comparison only approached significance (ChiSquare $=3.754$, df $=1, p=0.053$ ). No interaction was found between the main effects.

\section{Discussion}

\section{(1) Neurological aspects}

NV fits into the group of patients affected by progressive language disorder without dementia, the nature of which is likely to be degenerative. ${ }^{616-21}$ The evolution of his disturbances was rather slow and no significant worsening was detected between the first and the second examinations. However, on close inspection there was a slight decline in some verbal performances.

The CT scan of our patient showed atrophy of the inferior part of the perisylvian region. The lacunar defect in the body of the left caudate nucleus is not likely to be responsible for the clinical picture of NV, in view of his slowly progressive deterioration, unless we postulate that an underlying degenerative disease should first be manifest by symptoms related to a more brittle functional system: in our case, this would be the functional system subserving language skills, since lesions confined to deep left hemisphere structures can well give rise to language disturbances. ${ }^{22}$ However, if our patient had been affected by an overall dementia, we probably would have found a more generalised derangement in the course of the neuropsychological follow-up; 7 months is considered sufficient to discriminate between the evolution of
SDAT and Benign Senile Forgetfulness. ${ }^{23}$ Although most cases of progressive aphasia without dementia present with an amnestic aphasia, other language disturbances are also described, and in this respect, these cases do not form a homogeneous syndrome. ${ }^{19}$

\section{(2) Neuropsychological aspects}

From the neuropsychological point of view, our patient appeared to suffer from an isolated lexicalsemantic disturbance evident in both verbal comprehension and naming, that unevenly affected different semantic categories; comprehension of names of animals and fruits and vegetables was significantly worse than that of inanimate objects and especially means of transport. This dissociation replicates the findings of other investigators. ${ }^{3-5}$

Warrington and Shallice ${ }^{3}$ and Shallice ${ }^{24}$ distinguish between defects due to degradation of semantic store (that is, a permanent loss of information) and difficulties in access to the stored information, and suggest some criteria to differentiate between these possibilities. Our patient showed a high consistency in two different examinations, and his performance was influenced both by word frequency and by the category of the stimulus. Moreover, during language rehabilitation, his naming did not improve with semantic suggestion, that is, after a priming procedure. All these data lead to the conclusion that NV suffered from a degradation of the semantic store. A further criterion suggested by Warrington and Shallice for the diagnosis of semantic degradation is the sparing of some superordinate information, and this was found in fact in our case, but the breakdown of NV's semantic knowledge appeared rather more complex, as even at the subordinate level part of the information was retained. This aspect has been observed in other cases affected by a degradation of the semantic store. ${ }^{25}$

Warrington and McCarthy ${ }^{2}$ and Warrington and Shallice, ${ }^{3}$ describing cases with category-specific disturbances, observed that the knowledge of items belonging to different categories may rely differently on sensory and functional attributes. For the items for which our patient was unable to match name and 
picture (table 2), we found (table 3) that the functional attributes were substantially spared, as was the upper level superordinate knowledge. On the contrary, verbal knowledge of sensory attributes was severely affected and successful performance was at the level of chance. Obviously we are not claiming that NV's defect was pure in this respect, but only that he showed a striking dissociation between functional and physical attributes, which was evident mainly in verbal auditory comprehension.

In the visual categorisation task, NV performed rather well, and this indicates that the patient was not visually agnosic. However, here we must take into account the level of semantic knowledge which the task demanded: NV could visually categorise items at the upper superordinate level, but here he was proficient even in a purely verbal task (table 3). More interesting was the fact that visually he could perfectly categorise animals into mammals, birds and insects $(27 / 27$, chance $=9$, SD 2.45), whereas at the same semantic level he verbally scored $9 / 20$ with animals (chance $=5$, SD 1.94). This outcome would indicate that, at comparable levels of semantic complexity, the visual task was performed better than the verbal one. On the other hand, this cannot be a reliable indication of completely spared ability within the non-verbal domain, for the following reasons: (1) as language allows a deeper and more detailed inquiry into the semantic system than visual categorisation tasks do, details of non-verbal semantic knowledge of our patients were not sufficiently explored; (2) visual tasks could be less difficult than verbal ones, as superordinate information could be more easily retrieved from a picture than from a spoken word. Moreover, also the visual categorisation between fruits and vegetables was rather defective $(12 / 18$, chance $=$ 9$, SD $2 \cdot 1)$. In the latter case, the patient overtly used a verbal strategy to overcome the task, and to decide whether a given item belonged to the category of fruits or to that of vegetables he rather doubtfully asked himself whether it was to be cooked or to be eaten raw (that is, something like a functional aspect); the resort to a verbal strategy may indicate that in this situation his visuo-semantic knowledge was not itself available or was deranged.

It is interesting to note that in the general neuropsychological scenario of our patient the only defects discovered besides verbal naming and verbal comprehension were found in two overtly non-verbal semantic tasks: the colour-figure matching test and the sound-to-picture matching test. Considering that NV's semantic disturbances were mainly concerned with the physical attributes of the items, it is perhaps not surprising that he was defective in these tasks. In the sound-picture matching, the errors of NV were not confined to the categories deranged in the verbal task; he correctly matched the sounds of the alarm clock, sparrows, cock, drum, donkey, telephone, train, pianola, saw, hornet and cow with the corresponding pictures; and was wrong with motorcycle, cat, duck, bicycle bell, sheep, motorcar, horse, ambulance and baby's cry. This might suggest that, on the whole, the defect of NV was not strictly confined to some semantic categories, but was also concerned with the knowledge of some detailed physical attributes of other semantic units.

Professor Franco Denes (University of Padua) kindly provided part of the material employed in the examination of our patient.

\section{References}

1 Goodglass H, Wingfield A, Hyde MR, Theurkauf JC. Category specific dissociations in naming and recognition by asphasic patients. Cortex 1986;22:87-102.

2 Warrington EK, McCarthy R. Category specific access dysphasia. Brain 1983;106:859-78.

3 Warrington EK, Shallice T. Category specific semantic impairments. Brain 1984;107:829-53.

4 Hart J, Berndt RS, Caramazza A. Category-specific naming deficit following cerebral infarction. Nature 1985;316:439-40.

5 Sartori G, Job R. The oyster with four legs: a neuropsychological study on the interaction of visual and semantic information. Cognitive Neuropsychology 1988;5:105-32

6 Mesulam M-M. Slowly progressive aphasia without generalised dementia. Ann Neurol 1982;11:592-8.

7 Basso A, Capitani E, Vignolo LA. Influence of rehabilitation on language skills in aphasic patients. A controlled study. Arch Neurol 1979;36:190-6.

8 De Renzi E, Faglioni P. Normative data and discriminative power of a shortened version of the Token Test. Cortex 1978;14:41-49.

9 Capitani E, Laiacona M. Aging and psychometric diagnosis of intellectual impairment: some considerations on test scores and their use. Developmental Neuropsychology, (in press).

10 Spinnler H, Tognoni G, (Eds.) Standardizzazione e Taratura Italiana di Test Neuropsicologici Italian J Neurol Sci, Suppl.n.8, 1987.

11 Benton AL, Hamsher K de S, Varney NR, Spreen O. Contributions to Neuropsychological Assessment. A Clinical Manual. Oxford University Press, 1983.

12 Novelli G, Papagno C, Capitani E, Laiacona M, Vallar G, Cappa SF. Tre test clinici di ricerca e produzione lessicale. Taratura su soggetti normali. Archivio di Psicologia, Neurologia Psichiatria 1986;4:477-506.

13 Bortolini U, Tagliavini C, Zampolli A. Lessico di frequenza della lingua italiana contemporanea. Milan Garzanti 1972.

14 Cohen J. A coefficient of agreement for nominal scales. Educational and Psychological Measurement 1960;20:37-46.

15 Snodgrass JG, Vanderwart M. A standardizet set of 260 Pictures: Norms for Name Agreement, Image Agreement, Familiarity, and Visual Complexity. J Exp Psychol: Hum Learn Mem Cogn 1980;6:174-215.

16 Heath PD, Kennedy P, Kapur P. Slowly progressive aphasia without generalised dementia. Ann Neurol 1983;13:687-8.

17 Kirshner HS, Webb WG, Kelly MP, Wells CE. Language disturbance. An initial symptom of cortical degenerations and dementia. Arch Neurol 1984;41:491-6.

18 Assal G, Favre C, Regli F. Aphasie degenérative. Rev Neurol (Paris) 1985;141:245-7.

19 Poeck K, Luzzati C. Slowly progressive aphasia in three patients. The problem of accompanying neuropsychological deficit. Brain 1988;111:151-68.

20 Chawluk JB, Mesulam MM, Hurtig H, et al. Slowly Progressive Aphasia without Generalised Dementia: Studies with Positron Emission Tomography. Ann Neurol 1986;19:68-74. 
21 Wechsler AF. Presenile dementia presenting as aphasia. J Neurol Neurosurg Psychiatry 1977;40:303-5.

22 Basso A, Della Sala S, Farabola M. Aphasia arising from purely deep lesions. Cortex 1987;23:29-44.

23 Della Sala S, Nichelli P, Spinnler H. An Italian series of patients with organic Dementia. Ital J of Neurol Sci 1986;7:27-41.

24 Shallice T. Impairments of semantic processing: multiple dissociations. In: Coltheart $\mathrm{M}$, Sartori $\mathrm{G}$, Job $\mathrm{R}$, eds. The Cognitive Neuropsychology of Language. London: LEA, 1987.

25 Warrington EK. The selective impairment of semantic memory. Q J Exp Psychol 1975;27:635-57.

26 Basso A, Capitani E, Laiacona M. Raven's Colored Progressive

Appendix

General neuropsychological assessment
Matrices: Normative Values on 305 Adult normal controls. Functional Neurology 1987;2:189-94.

27 Novelli G, Papagno C, Capitani E, Laiacona M, Cappa SF, Vallar G. Tre test clinici di memoria verbale a lungo termine. Taratura su soggetti normali. Archivo di Psicologia, Neurologia e Psichiatria 1986;2:278-96.

28 Basso A, Capitani E. Un test standardizzato per la diagnosi di acalculia. Descrizione e valori normativi. AP-Rivista di applicazioni psicologiche 1979;1:551-64.

29 De Renzi E, Motti F, Nichelli P. Imitating gestures: a quantitative approach to ideomotor Apraxia. Arch Neurol 1980;37:6-10.

\begin{tabular}{|c|c|c|c|c|c|c|c|}
\hline & \multirow[t]{2}{*}{ Ist raw score } & \multirow[t]{2}{*}{ 2nd raw score } & \multicolumn{5}{|c|}{ Equivalent scores (1st* $2 n d \dagger)$} \\
\hline & & & 0 & 1 & 2 & 3 & 4 \\
\hline $\begin{array}{l}\text { Language } \\
\text { Token Test } \\
\text { Naming on description }{ }^{12} \\
\text { Object naming from photographs }{ }^{12} \\
\text { Verbal fluency from phonological cue }^{12} \\
\text { Verbal fluency from semantic cue }\end{array}$ & $\begin{array}{l}32 / 36 \\
21 \cdot 5 / 38 \\
11 / 32 \\
\text { NE } \\
\text { NE }\end{array}$ & $\begin{array}{l}31 / 36 \\
19 \cdot 5 / 38 \\
11 / 32 \\
10 \\
3\end{array}$ & $\begin{array}{l}*+ \\
*+ \\
+\end{array}$ & $\dagger$ & & $\dagger$ & * \\
\hline $\begin{array}{l}\text { General intelligence } \\
\text { PM } 47^{26} \\
\text { Weigl's test }\end{array}$ & $\begin{array}{l}33 / 36 \\
\mathrm{NE}\end{array}$ & $\begin{array}{l}32 / 36 \\
10 / 15\end{array}$ & & & & & $\stackrel{*}{\dagger}+$ \\
\hline $\begin{array}{l}\text { Memory } \\
\text { Digit span } \\
\text { Spatial span } \\
\text { Bisyllabic word span } \\
\text { Learning a 10-word list }^{27} \\
\text { Paired associate learning } \\
\text { Recall of brief tale } \\
\text { Learning a spatial sequence } \\
\text { Learno }\end{array}$ & $\begin{array}{l}6 \\
5 \\
4 \\
5 / 30 \\
6 / 22 \cdot 5 \\
8 \cdot 5 / 28 \\
19 \cdot 51 / 29 \cdot 16\end{array}$ & $\begin{array}{l}6 \\
6 \\
3 \\
7 / 30 \\
6 / 22 \cdot 5 \\
9 \cdot 5 / 28 \\
27 \cdot 18 / 29 \cdot 16\end{array}$ & & $\dagger$ & $*$ & $\begin{array}{l}* \\
\dagger \\
*\end{array}$ & $\begin{array}{l}* \dagger \\
* \dagger \\
+ \\
+\end{array}$ \\
\hline $\begin{array}{l}\text { Apraxia } \\
\text { Oral apraxia } \\
\text { Constructional apraxia }\end{array}$ & $\begin{array}{l}20 / 20 \\
14 / 14\end{array}$ & $\begin{array}{l}18 / 20 \\
13 / 14\end{array}$ & & $\dagger$ & & & $*$ \\
\hline $\begin{array}{l}\text { Visuo-perceptual skills } \\
\text { Line length discrimination } \\
\text { Discrimination of meaningless pictures } \\
\text { Visual form discrimination }^{11} \\
\text { Tactile form perception }^{11} \\
\text { Facial recognition } \\
\text { Judgement of line orientation }^{11}\end{array}$ & $\begin{array}{l}28 / 32 \\
\mathrm{NE} \\
30 / 32 \\
20 / 20 \\
44 / 54 \\
28 / 30\end{array}$ & $\begin{array}{l}26 / 32 \\
32 / 32 \\
30 / 32 \\
20 / 20 \\
38 / 54 \\
26 / 30\end{array}$ & & & $\dagger$ & $*$ & $\begin{array}{l}{ }^{*} \dagger \\
\dagger \\
* \dagger \\
* \\
* \dagger\end{array}$ \\
\hline $\begin{array}{l}\text { Calculation } \\
\text { Acalculia test }^{28}\end{array}$ & $92 / 101$ & $87 / 101$ & & & & & $* \dagger$ \\
\hline $\begin{array}{l}\text { Colouring } \\
\text { Colour-figure matching test } \ddagger\end{array}$ & $5 / 8$ & $5 / 8$ & ${ }^{*} \dagger$ & & & & \\
\hline $\begin{array}{lr}\text { Ideomotor apraxia }^{29} & \\
\text { WAIS total }^{2} & 98 \\
\text { verbal } & 94 \\
\text { performance } & 106\end{array}$ & $66 / 72$ & $68 / 72$ & (cu & ff: 5 & & & \\
\hline Sound-picture matching tests $\ddagger$ & & $11 / 20$ & $\begin{array}{l}\text { (me } \\
18 \cdot \varepsilon\end{array}$ & & & s: & \\
\hline
\end{tabular}

Key: NE = not examined. Whenever the reference is not indicated, it is to ref 10 . $\ddagger$ unpublished data. 